\title{
The Analysis of Leakage Current on a 20-kV Silicone Rubber Post-Insulator under Dry and Wet Conditions
}

\author{
Moch Dhofir $^{\# 1}$, Mukti Friyan Aditama ${ }^{\# 2}$, Rini Nur Hasanah ${ }^{\# 3}$, Hadi Suyono ${ }^{\# 4}$ \\ ${ }^{\#}$ Department of Electrical Engineering, Brawijaya University, Jl. MT Haryono 167 Malang, 65145, Indonesia \\ E-mail: ${ }^{1}$ dhofir@ub.ac.id; ${ }^{2}$ friyan.aditama@gmail.com; ${ }^{3}$ rini.hasanah@ub.ac.id; ${ }^{4}$ hadis@ub.ac.id
}

\begin{abstract}
Silicone rubber material has not been commonly used in the manufacturing of a post insulator. As the installation of this insulator type is normally in an open space, it is greatly vulnerable to the influence of weather and environment, such as humidity, rain water, lightning strikes, temperature, ultraviolet radiation, and others. Leakage currents flowing on its surface may become the source of power losses. This article presents the results of research on the effect of voltage and wetting intensity on the leakage current level of a $20-\mathrm{kV}$ silicone-rubber post-insulator. The leakage current has been observed under dry and wet conditions. The experiment has been conducted using the voltage level variation of $5 \mathrm{kV}$ in the range between $10 \mathrm{kV}$ and $30 \mathrm{kV}$, using four variations of wetting intensity. Comparison of the experiment results showed that unlike under the dry condition, the resulted leakage current under the wet condition increased nonlinearly with the increase in the wetting intensity and the voltage level.
\end{abstract}

Keywords — Leakage-current; post-insulator; silicone-rubber; wetting intensity.

\section{INTRODUCTION}

The continuously increasing need of electrical energy requires the provision of adequate power generation and reliable transmission lines to deliver electricity from power plants to consumers [1],[2]. A power transmission system involves a large number of supporting equipment, among other is an insulator. The insulator serves as a support to the conductors in the tower of a power transmission system. It is electrically used to separate two or more wires in order to prevent the occurrence of leakage current or flashover which may bring the damage to the power system grid [3]-[5].

The insulators generally are installed outdoor, in an open space, so that it can be affected by the condition of weather and the surrounding environment, for example, the influence of moisture, rain water, lightning strikes, temperature, ultraviolet radiation, and others. Environmental influences may lead to a decrease in the working performance of the insulators to below its rating design. It may be followed by the insulation failure. The generated leakage current will also bring about the power losses in the transmission line.

Glass and ceramics are widely used as materials for insulators. This type of insulator possesses some disadvantages because of the changes in surface resistance under wet condition. It may lead to a higher possibility of current leakage occurrence. There has been recent development to use the silicone-rubber polymer material for insulators, as it provides some advantages being compared to ceramics and glass materials. The benefit includes its light weight, resistance to vandalism, better performance in the polluted and wet conditions, and is comparable or even better in withstanding high voltage than a porcelain or glass insulator [6]-[13].

This paper presents the results of a study on the effect of voltage and wetting conditions on the leakage current of a post-insulator made from silicone rubber.

\section{MATERIAL AND METHOD}

Some conditions, materials and the method adopted in the research are elaborated as follows.

\section{A. The Rainfall Condition}

Rainfall is defined as the height of collected rainwater in a flat, non-volatile, non-permeable, and non-flowing place. One milliliter rainfall represents the condition of $1 \mathrm{~m}^{2}$ of flat-place area which accommodates water of $1 \mathrm{~mm}$ of height, which also means that it contains one liter of water. The rain intensity is defined as the amount of rainfall during the certain period of time. It is measured using an ombrometer and expressed in millimeter per hour $(\mathrm{mm} / \mathrm{h})$ unit [14],[15]. The rainfall in tropical countries like Indonesia can be categorized according to its level of intensity: light rain $(1-5 \mathrm{~mm} / \mathrm{h})$, medium $(5-10 \mathrm{~mm} / \mathrm{h})$, heavy rain $(10-20 \mathrm{~mm} / \mathrm{h})$ and very heavy rain (more than $20 \mathrm{~mm} / \mathrm{h}$ ) [16],[17]. 


\section{B. A Silicone Rubber Post-Insulator}

An insulator has a function to separate electrical components, as well as to separate the electrical part from the other non-electrical parts. A post-type insulator, as shown in Fig. 1, is constructed in the form of a cylinder, equipped with a cap on the upper-part, and pegs made of iron or steel on the lower-part. This type of insulators is usually made of cheap, wet-porcelain materials [3]-[5].

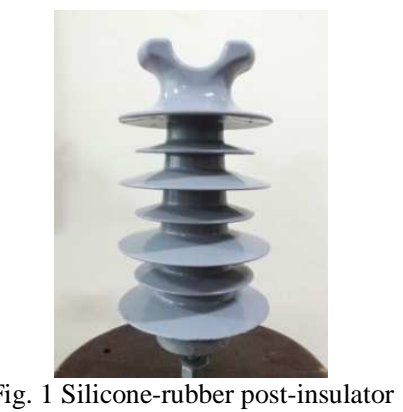

The preparation of silicone rubber materials can be done by vulcanization of PDMS polymer, covering the curing process to make the long molecules interlinked each-other through the condensation process. In order to adapt to the required insulator type, the fabrication process can be carried out using room temperature or high-temperature condition with different catalysts [6].

\section{The Leakage Current of Insulator}

In a clean state, the surface of an insulator has a large electrical resistance. The formation of a conductive layer on its surface is commonly caused by the contamination of water on the insulator surface. The conductive layer may cause the deterioration of the surface resistance, and furthermore may produce the leakage current occurrence on the surface.

The leakage current is a function of the contaminated surface resistance value of the insulator. Its decrease will be accompanied by the increase in the leakage current of the insulator surface. Based on the prevailing Ohm's law, the electric current $(I)$ flowing in a material is directly proportional to the voltage $(V)$ across it, and inversely proportional to the resistance $(R)$, as expressed in Eq. (1).

$$
I=\frac{V}{R}
$$

The information about the surface resistance $\left(R_{\mathrm{S}}\right)$ is useful to determine the value of power losses $\left(P_{\text {loss }}\right)$ and annual energy losses being caused by the leakage current $\left(I_{\mathrm{lc}}\right)$, using Eq. (2) and Eq. (3) consecutively,

$$
\begin{gathered}
P_{\text {loss }}=I_{l c}^{2} R_{s} \\
W_{\text {loss }}=8760 P_{\text {loss }}
\end{gathered}
$$

\section{Insulator Surface Contact Engle}

There are two main properties of a substance, which are water absorbing (hydrophilic) or water repelling (hydrophobic) properties. An insulator made of silicone rubber has a surface characteristic which repels water better than the other insulating materials such as glass and ceramics [7]. The properties of the insulating materials can be known from the value of their surface contact angles. The contact angle is taken as the average of the right $\left(\alpha_{r}\right)$ and left $\left(\alpha_{l}\right)$ contact angles, as given by Eq. (4).

$$
\alpha=\frac{1}{2}\left(\alpha_{r}+\alpha_{l}\right)
$$

\section{E. The Experiment Steps to Follow}

The conducted research has been performed based on the main steps given in Fig. 2.

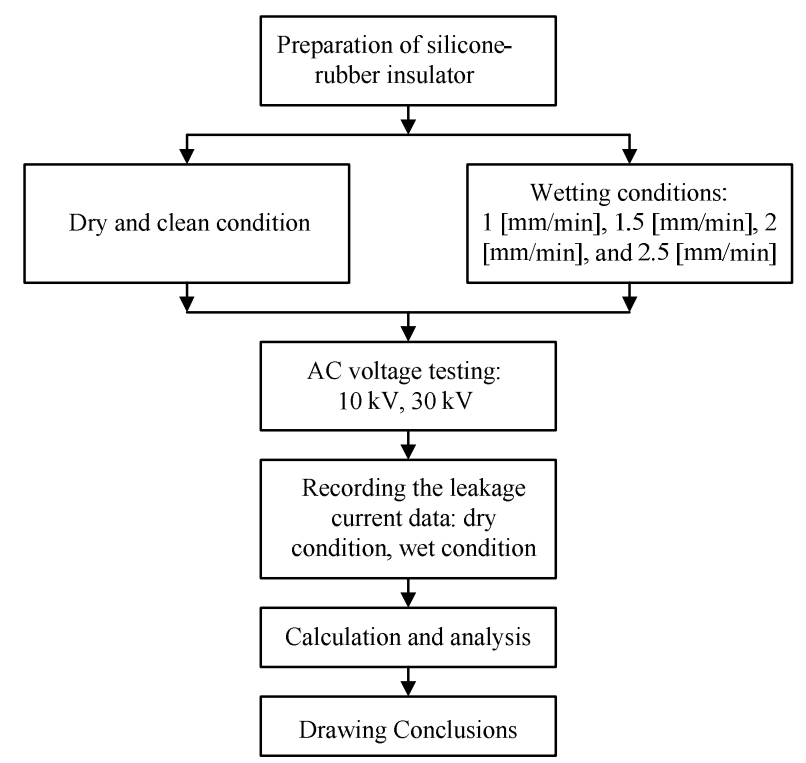

Fig. 2 Steps to carry out the experiment

\section{F. The Experimental Set-Up}

The experimental set-up for the observation of the leakage current observation in a silicone-rubber post-insulator under two different conditions is shown in Fig. 3.

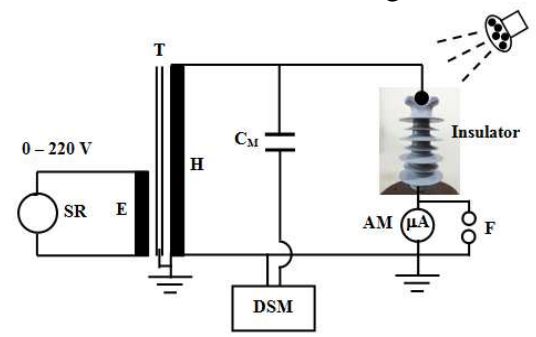

Fig. 3 The experimental set-up for leakage current observation

As indicated in Fig. 3, the symbol SR represents the slide regulator to adjust to input voltage, $\mathrm{T}$ is the testing transformer, $\mathrm{E}$ and $\mathrm{H}$ are the low-voltage and high-voltage windings of the transformer respectively, $\mathrm{CM}$ is the capacitor measurement, DSM is the instrument to measure the peak AC high-voltage, AM represents the $\mu$ amperemeter, whereas the $\mathrm{F}$ is the spark gap for overvoltage protection.

An alternating current (AC) has been used in the experiment to represent the actual conditions. The AC highvoltage applied to the silicon rubber insulator has been generated from the testing transformer. It can be used to generate the voltage up to $100 \mathrm{kV}_{\text {rms }}$. The high-voltage level can be changed by adjusting the input voltage at the lowvoltage winding $\mathrm{E}$. The output voltage of $100 \mathrm{kV}$ could be 
generated on the $\mathrm{H}$ winding when the low-voltage winding $\mathrm{E}$ is supplied with a voltage of $220 \mathrm{~V}$.

The range of voltage of $10-30 \mathrm{kV}$ has been used during the experiment. The applied working voltage has been increased gradually with an increase of $5 \mathrm{kV}$, and the leakage current was measured at each stage. At each stage, the working voltage has been maintained during 1 minute and the leakage current was measured again. The resulted leakage current has been observed directly using an amperemeter. The measured leakage currents represent the current flowing through the surface of the insulator. For each stage of the working voltage value, the experiment has been carried out three times and the average value has been taken.

For each voltage increase and wetting intensity, the leakage current on the insulator has been measured using a $\mu$-amperemeter mounted in series with the insulator. The spark gap from the arrangement of spherical electrodes was installed to secure the $\mu$-amperemeter from any possible overvoltage.

The voltage on the insulator was measured using the capacitor divider CM connected to the DSM instrument using a $75 \Omega$ coaxial cable. The intensity of wetting has been regulated by increasing the pressure of the shower through the increase of the water pump speed.

\section{RESULTS AND DISCUSSION}

The data obtained from the experiments include those from the leakage current testing under dry and wet conditions, the relationship between the voltage and the produced leakage current, the influence of wetting intensity to the surface resistance and power losses, as well as the data of the surface contact angles.

\section{A. Leakage Current Testing under Dry Condition}

The dry condition is represented by the wetting intensity of $0 \mathrm{~mm} / \mathrm{min}$. It corresponds to the actual insulator condition during the clear day. The influence of the applied voltage on the occurrence of leakage current has been examined using the voltage range of $10-30 \mathrm{kV}$, as shown in Table 1 . It can be known that the leakage current increases proportionally with the increase in the applied voltage.

TABLE I

THE EXPERIMENTAL DATA OF THE INSULATOR IN DRY CONDITION

\begin{tabular}{|c|c|c|c|c|}
\hline No. & $\begin{array}{c}\text { Voltage } \\
(\mathbf{k V})\end{array}$ & $\begin{array}{c}\text { Leakage } \\
\text { Current } \\
(\mu \mathrm{A})\end{array}$ & $\begin{array}{c}\text { Average } \\
\text { Voltage } \\
(\mathbf{k V}) \\
\end{array}$ & $\begin{array}{c}\text { Average } \\
\text { Current } \\
(\mathrm{kV}) \\
\end{array}$ \\
\hline \multirow{3}{*}{1} & 10.10 & 9.3 & \multirow{3}{*}{10.06} & \multirow{3}{*}{9.27} \\
\hline & 10.02 & 9.2 & & \\
\hline & 10.05 & 9.3 & & \\
\hline \multirow{3}{*}{2} & 15.08 & 14.3 & \multirow{3}{*}{15.06} & \multirow{3}{*}{14.27} \\
\hline & 15.00 & 14.2 & & \\
\hline & 15.09 & 14.3 & & \\
\hline \multirow{3}{*}{3} & 20.05 & 19.2 & \multirow{3}{*}{20.05} & \multirow{3}{*}{19.20} \\
\hline & 20.07 & 19.3 & & \\
\hline & 20.02 & 19.1 & & \\
\hline \multirow{3}{*}{4} & 25.02 & 24.2 & \multirow{3}{*}{25.06} & \multirow{3}{*}{24.27} \\
\hline & 25.09 & 24.3 & & \\
\hline & 25.07 & 24.3 & & \\
\hline \multirow{3}{*}{5} & 30.09 & 29.4 & \multirow{3}{*}{30.05} & \multirow{3}{*}{29.37} \\
\hline & 30.05 & 29.4 & & \\
\hline & 30.01 & 29.3 & & \\
\hline
\end{tabular}

\section{B. Leakage Current Testing under Wet Condition}

Like in the dry condition, the same tendency of leakage current change also occurred on the insulator under the wet condition. The experiment has been carried out using 4 variations of wetting intensities, i.e. $1.032 ; 1.526 ; 2.018$; and $2.512 \mathrm{~mm} /$ minute. The measured leakage currents in various wetting conditions are shown in Table 2 . The values in the table have been taken from the average of three times of experiment at each step.

TABLE II

THE EXPERIMENTAL DATA OF THE INSULATOR UNDER WET CONDITION

\begin{tabular}{|c|c|c|c|}
\hline No. & $\begin{array}{c}\text { Wetting Intensity } \\
(\mathrm{mm} / \mathrm{min})\end{array}$ & $\begin{array}{c}\text { Voltage } \\
(\mathbf{k V})\end{array}$ & $\begin{array}{c}\text { Leakage Current } \\
(\mu \mathrm{A})\end{array}$ \\
\hline \multirow{5}{*}{1} & \multirow{5}{*}{1.032} & 10.03 & 12.07 \\
\hline & & 15.02 & 18.17 \\
\hline & & 20.03 & 24.87 \\
\hline & & 25.03 & 31.23 \\
\hline & & 30.03 & 38.17 \\
\hline \multirow{5}{*}{2} & \multirow{5}{*}{1.526} & 10.04 & 13.47 \\
\hline & & 15.02 & 20.4 \\
\hline & & 20.03 & 27.33 \\
\hline & & 25.05 & 35.27 \\
\hline & & 30.03 & 43.17 \\
\hline \multirow{5}{*}{3} & \multirow{5}{*}{2.018} & 10.04 & 16.4 \\
\hline & & 15.03 & 24.63 \\
\hline & & 20.02 & 33.3 \\
\hline & & 25.04 & 45.17 \\
\hline & & 30.03 & 62.23 \\
\hline \multirow{5}{*}{4} & \multirow{5}{*}{2.512} & 10.04 & 18.5 \\
\hline & & 15.03 & 27.93 \\
\hline & & 20.04 & 45.57 \\
\hline & & 25.04 & 71.33 \\
\hline & & 30.03 & 118.23 \\
\hline
\end{tabular}

Table 2 enables to observe the relationship between the leakage current, the change in wetting intensity, and the applied voltage. The relationship between the voltage and the leakage current for each wetting intensity is presented more clearly in Fig. 4.

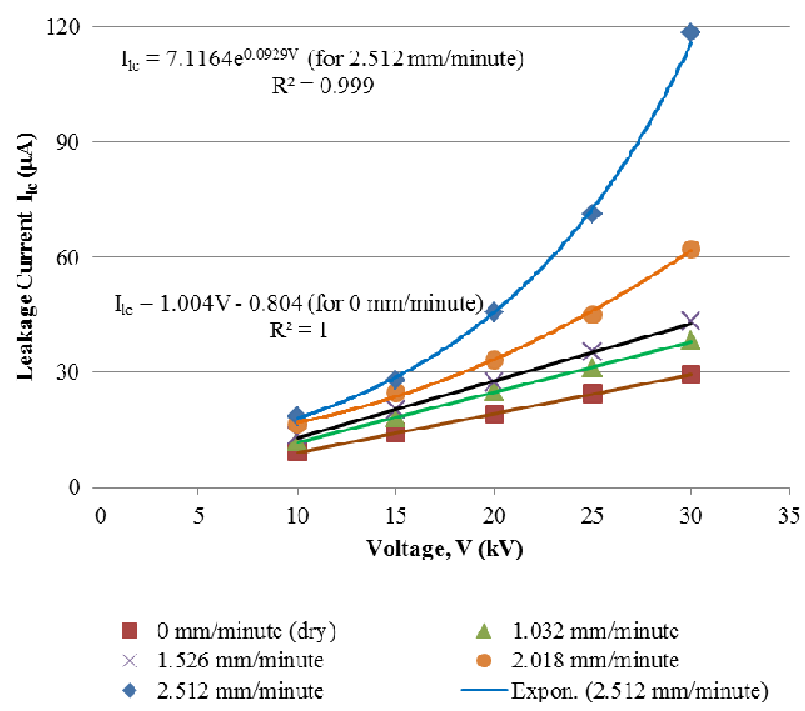

Fig. 4 The relationship between the applied voltage and the leakage current of insulator in dry and wet conditions 
The Ohm's Law in Eq. (1) implies that the relationship between the voltage and the current is linear. The ratio between the voltage and the current is of constant value, which is named as the resistance coefficient. The resulted experiment data in Table 2 and their related graphics in Fig. 4 indicate that this linear relationship is only valid up to the wetting intensity of around $1.526 \mathrm{~mm} /$ minute at the applied voltage of $30 \mathrm{kV}$. Under this condition the applied voltage increase will be followed linearly with the increase in the resulted leakage current level. However, beyond the wetting intensity of $1.526 \mathrm{~mm} /$ minute the relationship between the voltage and the current is not linear anymore. For the same value of voltage increase, the resulted leakage current increase will be higher. Under the highest wetting intensity of $2.512 \mathrm{~mm} / \mathrm{minute}$, the resulted leakage current Ilc of the silicone-rubber insulator in $\mu \mathrm{A}$ as a function of the applied voltage in $\mathrm{kV}$ can be approximated using an exponential equation with a determination coefficient of 0.999 as given in Eq. (5).

$$
\begin{array}{ll}
I_{l c} & =7.1164 e^{0.0929 V} \quad(\text { for } 2.512 \mathrm{~mm} / \text { minute }) \\
R^{2} & =0.999
\end{array}
$$

Equation (5) implies that the surface resistance of the insulator under the wetting intensity condition beyond the highest value of $1.526 \mathrm{~mm} /$ minute is influenced by the applied voltage level. Higher the applied voltage, lower will be the resulted resistance.

The phenomenon of current increase in an exponential way is due to the electrons production in the conductive layer. At a higher voltage level, the electric field intensity over the wet insulator surface is strong enough to free electrons from the collision of water and air molecules. The movement of free electrons in the air and in the water layer of the insulator surface will be accelerated in the electric field. The field increase due to the applied voltage increase will furthermore increase the velocity and the kinetic energy of the free electrons. The following collision with the molecules in the water layer and the air will free new more electrons, forming a chain reaction of electron freeing. The resulted number of free electrons, which means also the leakage current, increases exponentially with the applied voltage increase. The electrons production by the wet insulator surface will increase exponentially with the increase of the applied voltage.

As indicated by the curves in Fig. 4, there is a clear difference between the resulted leakage currents obtained using the smallest and highest wetting intensity conditions. Using the smallest wetting intensity of $1.052 \mathrm{~mm} / \mathrm{min}$ the leakage current rises linearly, whereas using higher wetting intensity the leakage current increase was not proportional to the applied voltage increase. It is because the higher the wet area coverage, the more conductive will be the insulator surface to let the leakage current flow more easily.

Fig. 4 also gives the information about the effect of different voltages and wetting intensities on the value of the leakage current flowing through the surface of the siliconerubber post-insulator. The testing voltage has been increased successively during the experiment. The resulted leakage current became more and more non-proportional to the increase in the wetting intensity given. It is because the water layer being formed on the surface becomes more and more even so that the conductive layer becomes larger.

\section{The Influence of the Wetting Intensity on the Surface Resistance}

The leakage current of an insulator depends on its surface resistance Rs. The results of the experiment on the surface resistance measurement in dry condition can be seen in Table 3.

TABLE III

THE INSUlator SURFACE RESISTANCE FOR EACH WETTING INTENSITY

\begin{tabular}{|c|c|c|c|c|}
\hline No. & $\begin{array}{c}\text { Wetting } \\
\text { Intensity } \\
(\mathbf{m m} / \mathbf{m i n})\end{array}$ & $\begin{array}{c}\text { Voltage } \\
(\mathbf{k V})\end{array}$ & $\begin{array}{c}\text { Leakage } \\
\text { Current } \\
(\mu \mathrm{A})\end{array}$ & $\begin{array}{c}\text { Surface } \\
\text { Resistance } \\
(\mathrm{M} \Omega)\end{array}$ \\
\hline \multirow{5}{*}{1} & \multirow{5}{*}{0 (dry) } & 10.06 & 9.27 & 1085.22 \\
\hline & & 15.06 & 14.27 & 1055.36 \\
\hline & & 20.05 & 19.2 & 1044.27 \\
\hline & & 25.06 & 24.27 & 1032.55 \\
\hline & & 30.05 & 29.37 & 1023.15 \\
\hline \multirow{5}{*}{2} & \multirow{5}{*}{1.032} & 10.03 & 12.07 & 830.98 \\
\hline & & 15.02 & 18.17 & 826.63 \\
\hline & & 20.03 & 24.87 & 805.38 \\
\hline & & 25.03 & 31.23 & 801.14 \\
\hline & & 30.03 & 38.17 & 786.74 \\
\hline \multirow{5}{*}{3} & \multirow{5}{*}{1.526} & 10.04 & 13.47 & 745.36 \\
\hline & & 15.02 & 20.4 & 739.9 \\
\hline & & 20.03 & 27.33 & 732.89 \\
\hline & & 25.05 & 35.27 & 710.23 \\
\hline & & 30.03 & 43.17 & 695.62 \\
\hline \multirow{5}{*}{4} & \multirow{5}{*}{2.018} & 10.04 & 16.4 & 612.19 \\
\hline & & 15.03 & 24.63 & 610.23 \\
\hline & & 20.02 & 33.3 & 601.2 \\
\hline & & 25.04 & 45.17 & 554.35 \\
\hline & & 30.03 & 62.23 & 482.56 \\
\hline \multirow{5}{*}{5} & \multirow{5}{*}{2.512} & 10.04 & 18.5 & 542.7 \\
\hline & & 15.03 & 27.93 & 538.13 \\
\hline & & 20.04 & 45.57 & 439.76 \\
\hline & & 25.04 & 71.33 & 351.04 \\
\hline & & 30.03 & 118.23 & 253.99 \\
\hline
\end{tabular}
AND APPLIED VOLTAGE

Based on the data in Tabel 3, the relationship between the surface resistance and the applied voltage for each wetting intensity, can be presented in Fig. 5. As shown, it is obvious that the wetting intensity influences the value of insulator surface resistance. In dry conditions, the surface resistance of an insulator has a large value. It is decreasing with the increase in the wetting intensity and the applied voltage, meaning that the insulator becomes more increasingly conductive. The greater the wetting intensity and voltage applied to the insulator, lower will be the surface resistance.

As can be observed from Fig. 5, the increase in wetting intensity and applied voltage was not continuously proportional to the decrease of surface resistance. From the data obtained, until the wetting intensity of 1.526 $\mathrm{mm} /$ minute, the decrease in surface resistance is linearly proportional to the increase in the applied voltage. On the other hand, using the higher wetting intensity data, it can be seen that the value change in insulator surface resistance was not linear anymore with the increase in the applied voltage. The wetter the surface condition, more evenly will be the distribution of the conductive layer. The resistance will 
decrease faster, resulting in the non-linear trend of surface resistance with respect to the applied voltage.

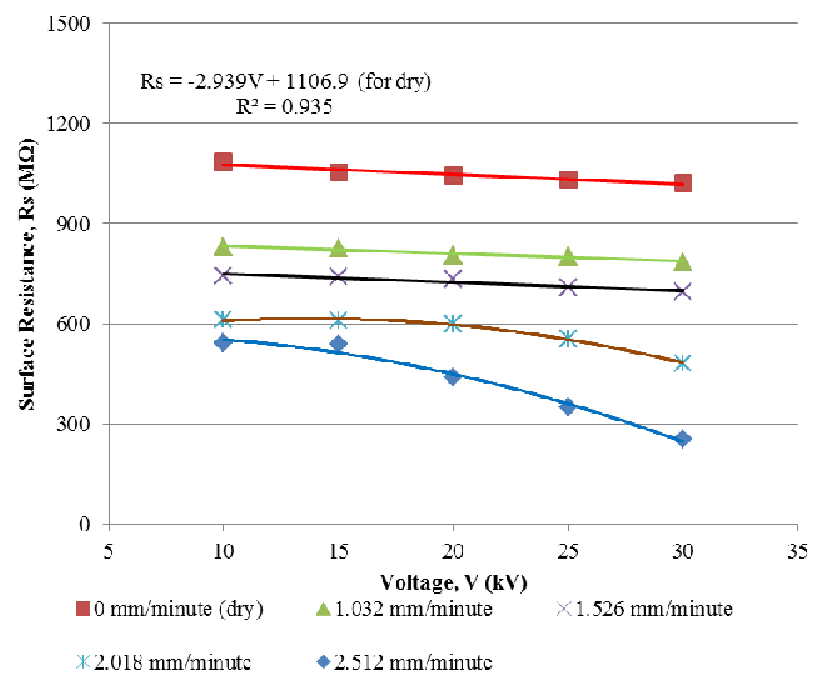

Fig. 5 The relationship between the surface resistance and the applied voltage for each wetting intensity

Based on Eq. (5), the surface resistance of the insulator $\mathrm{M} \Omega$ unit under the highest wetting intensity of 2.512 $\mathrm{mm} /$ minute can be expressed as in Eq. (6).

$$
R_{s}=\frac{V}{I_{l c}}=\frac{V}{7.1164 e^{0.0929 V}}
$$

\section{The Influence of the Wetting Intensity on the Power Losses}

The large value of leakage current flowing on the surface of an insulator indicates the highly conductive property of the surface and leads to the deterioration of the insulator ability to isolate a high-voltage region zone. The power losses being caused by the leakage current can be calculated using Eq. 2. The calculation results of the power losses on the insulator under dry and wet conditions are presented in Table 4.

The power losses, their respective influence on the leakage current flowing through the insulator surface can be represented using Fig. 6. As indicated, the wetting intensity increase will increase the power losses. For the same value of the applied voltages, the resulted losses will be significantly different if the wetting intensities are different. Higher the wetting intensity, larger will be the power losses.

Based on the curve in Fig, 6, it can be understood that up to the wetting intensity of $1.526 \mathrm{~mm} /$ minute, the change in the value of annual energy losses follows the applied voltage increase trend linearly, but based on the higher wetting intensity data, the losses increase became more and more faster.

At the applied voltage of $30 \mathrm{kV}$, the resulted power loss was $0.8826 \mathrm{~W}$ under the dry condition or wetting intensity of $0 \mathrm{~mm} / \mathrm{minute}$, but increased up to around 4 times higher or 3.5504 when the wetting intensity was increased up to 2.512 $\mathrm{mm} /$ minute. For the application in a $20-\mathrm{kV}$ system the insulator is only subjected to the AC voltage of $11.54 \mathrm{kV}$, which produces a leakage current level of around $20 \mu \mathrm{A}$ under the highest wetting intensity condition and around 10 $\mu \mathrm{A}$ under the dry condition.

TABLE IV

THE POWER LOSSES FOR EACH WeTtING INTENSITY AND APPLIED VOLTAGE

\begin{tabular}{|c|c|c|c|c|}
\hline No. & $\begin{array}{c}\text { Wetting } \\
\text { Intensity } \\
(\mathrm{mm} / \mathrm{min})\end{array}$ & $\begin{array}{c}\text { Voltage } \\
(\mathbf{k V})\end{array}$ & $\begin{array}{c}\text { Leakage } \\
\text { Current } \\
(\mu \mathrm{A})\end{array}$ & $\begin{array}{c}\text { Power } \\
\text { Losses } \\
(W) \\
\end{array}$ \\
\hline \multirow{5}{*}{1} & \multirow{5}{*}{0 (dry) } & 10.06 & 9.27 & 0.0933 \\
\hline & & 15.06 & 14.27 & 0.2149 \\
\hline & & 20.05 & 19.2 & 0.385 \\
\hline & & 25.06 & 24.27 & 0.6082 \\
\hline & & 30.05 & 29.37 & 0.8826 \\
\hline \multirow{5}{*}{2} & \multirow{5}{*}{1.032} & 10.03 & 12.07 & 0.1211 \\
\hline & & 15.02 & 18.17 & 0.2729 \\
\hline & & 20.03 & 24.87 & 0.4981 \\
\hline & & 25.03 & 31.23 & 0.7814 \\
\hline & & 30.03 & 38.17 & 1.1462 \\
\hline \multirow{5}{*}{3} & \multirow{5}{*}{1.526} & 10.04 & 13.47 & 0.1352 \\
\hline & & 15.02 & 20.4 & 0.3049 \\
\hline & & 20.03 & 27.33 & 0.5474 \\
\hline & & 25.05 & 35.27 & 0.8835 \\
\hline & & 30.03 & 43.17 & 1.2964 \\
\hline \multirow{5}{*}{4} & \multirow{5}{*}{2.018} & 10.04 & 16.4 & 0.1647 \\
\hline & & 15.03 & 24.63 & 0.3702 \\
\hline & & 20.02 & 33.3 & 0.6667 \\
\hline & & 25.04 & 45.17 & 1.1311 \\
\hline & & 30.03 & 62.23 & 1.8687 \\
\hline \multirow{5}{*}{5} & \multirow{5}{*}{2.512} & 10.04 & 18.5 & 0.1857 \\
\hline & & 15.03 & 27.93 & 0.4198 \\
\hline & & 20.04 & 45.57 & 0.9132 \\
\hline & & 25.04 & 71.33 & 1.7861 \\
\hline & & 30.03 & 118.23 & 3.5504 \\
\hline
\end{tabular}

Figure 6 indicates the relationship between the power losses in watt units and the applied voltage in $\mathrm{kV}$ units. For the highest wetting intensity condition, the relationship can be approximated using an exponential equation in Eq. (7).

$$
\begin{aligned}
& P_{\text {loss }}=0.0447 e^{0.1473 V} \\
& R^{2}=0.9979
\end{aligned}
$$

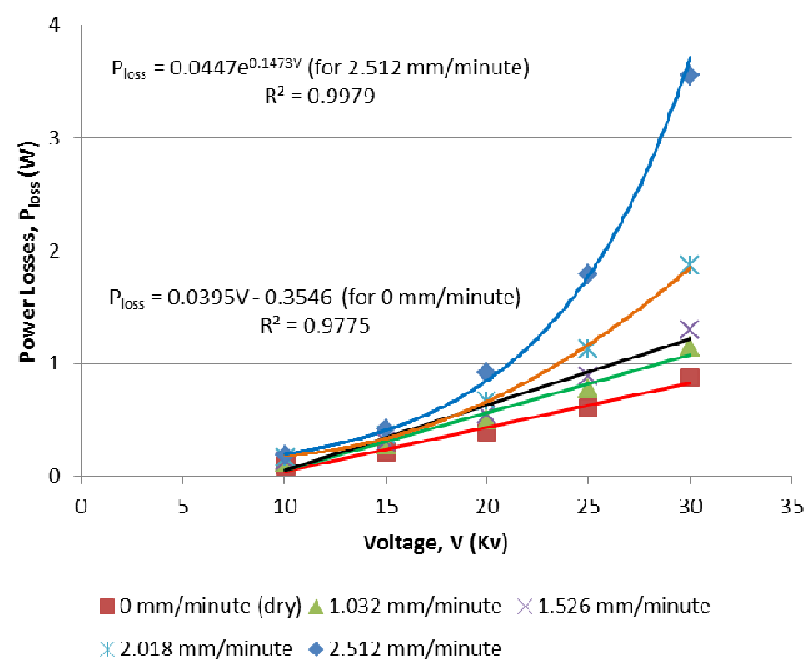

Fig. 6 The relationship between the power losses and the applied voltage for each wetting intensity 
Table 4 and Fig. 6 also show that increasing the working voltage will increase the power losses on the silicone-rubber post-insulator both under dry and wet conditions. It is because the applied voltage $\mathrm{V}$ across the electrodes (between the anode and the cathode) will create an electric field $\mathrm{E}$ with certain direction and value. Under the influence of this electric field, the free electrons will get an enough energy to accelerate its movement, so as to stimulate the ionization process. If the existing voltage gradient continues to increase, the number of the ionized electrons will be even greater than the number of ions being captured to form the oxygen molecules. The ionized electrons will move toward the anode continuously while colliding and freeing up even more electrons along their paths. The continuously increasing number of electrons released will create an electrons avalanche. As the electrons movement, whose direction is the opposite of the current direction, depends on the applied voltage, then the higher the voltage applied between the two electrodes, the greater will be the flowing current and energy losses.

\section{E. The Influence of the Wetting Intensity on the Annual Energy Losses}

The annual energy losses have been calculated from the multiplication of the power losses data in Table IV with the number of hours during a year, i.e. 8760 hours. The results of annual energy losses are shown in Table V.

TABLE V

THE ANNUAL ENERGY LOSSES FOR EACH WETTING INTENSITY AND APPLIED VOLTAGE

\begin{tabular}{|c|c|c|c|c|}
\hline No. & $\begin{array}{c}\text { Wetting } \\
\text { Intensity } \\
(\mathrm{mm} / \mathrm{min})\end{array}$ & $\begin{array}{c}\text { Voltage } \\
(\mathrm{kV})\end{array}$ & $\begin{array}{c}\text { Leakage } \\
\text { Current } \\
(\mu \mathrm{A})\end{array}$ & $\begin{array}{c}\text { Energy } \\
\text { Losses } \\
\text { (Wh) }\end{array}$ \\
\hline \multirow{5}{*}{1} & \multirow{5}{*}{0 (dry) } & 10.06 & 9.27 & 816.92 \\
\hline & & 15.06 & 14.27 & 1882.58 \\
\hline & & 20.05 & 19.2 & 3372.25 \\
\hline & & 25.06 & 24.27 & 5327.88 \\
\hline & & 30.05 & 29.37 & 7731.28 \\
\hline \multirow{5}{*}{2} & \multirow{5}{*}{1.032} & 10.03 & 12.07 & 1060.5 \\
\hline & & 15.02 & 18.17 & 2390.7 \\
\hline & & 20.03 & 24.87 & 4363.72 \\
\hline & & 25.03 & 31.23 & 6844.73 \\
\hline & & 30.03 & 38.17 & 10041.06 \\
\hline \multirow{5}{*}{3} & \multirow{5}{*}{1.526} & 10.04 & 13.47 & 1184.69 \\
\hline & & 15.02 & 20.4 & 2670.97 \\
\hline & & 20.03 & 27.33 & 4795.37 \\
\hline & & 25.05 & 35.27 & 7739.52 \\
\hline & & 30.03 & 43.17 & 11356.39 \\
\hline \multirow{5}{*}{4} & \multirow{5}{*}{2.018} & 10.04 & 16.4 & 1442.37 \\
\hline & & 15.03 & 24.63 & 3242.85 \\
\hline & & 20.02 & 33.3 & 5839.98 \\
\hline & & 25.04 & 45.17 & 9908.05 \\
\hline & & 30.03 & 62.23 & 16370.24 \\
\hline \multirow{5}{*}{5} & \multirow{5}{*}{2.512} & 10.04 & 18.5 & 1627.07 \\
\hline & & 15.03 & 27.93 & 3677.33 \\
\hline & & 20.04 & 45.57 & 7999.78 \\
\hline & & 25.04 & 71.33 & 15646.07 \\
\hline & & 30.03 & $3^{118.2}$ & $.13^{31101}$ \\
\hline
\end{tabular}

The graphical relationship between the increase in the produced annual energy losses and the applied voltage increase for various wetting conditions is displayed in Fig. 7. As the energy losses are proportional to the power losses, the resulted curves are similar each other. The resulted energy losses as a function of the applied voltage under the highest wetting intensity of $2.512 \mathrm{~mm} /$ minute can be approached using an exponential equation in Eq. (8).

$$
\begin{aligned}
& W_{\text {loss }}=395.18 e^{0.147 V} \\
& R^{2}=0.9981
\end{aligned}
$$

With an applied voltage of $30 \mathrm{kV}$ and the highest wetting intensity of $2.512 \mathrm{~mm} / \mathrm{minute}$, the resulted energy losses were around $31101 \mathrm{Wh}$ or 4 times higher than under dry condition with the wetting intensity of $0 \mathrm{~mm} /$ minute.

For insulator application at the voltage of $11.54 \mathrm{kV}$ (the $20 \mathrm{kV}$ system), the obtained energy losses were around 2500 Wh under the wetting intensity of $2.512 \mathrm{~mm} /$ minute and around $1200 \mathrm{Wh}$ under the dry condition respectively.

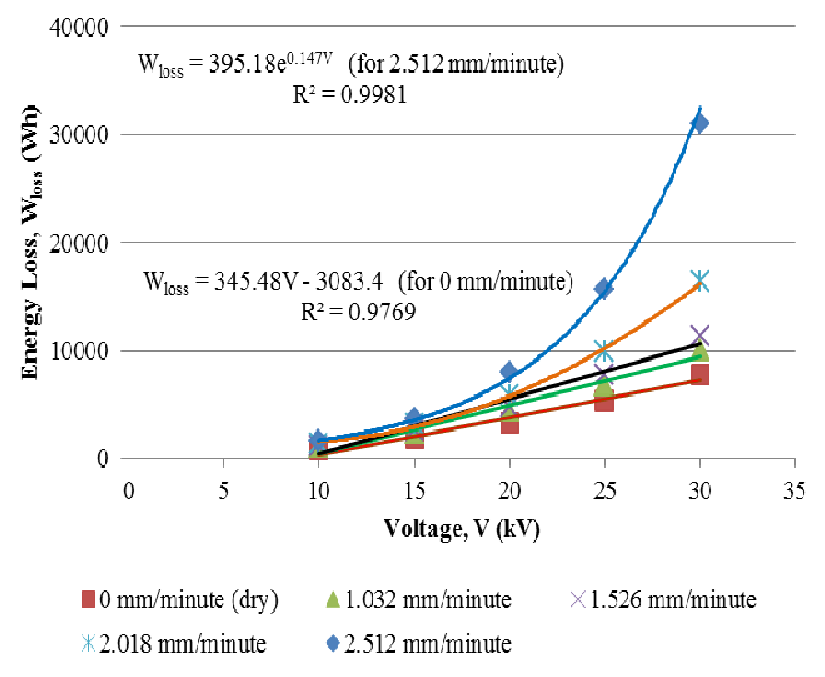

Fig. 7 The relationship between the annual energy losses and the applied voltage for each wetting intensity

\section{F. Analysis of the Contact Angle}

The property of insulator material, whether it is hydrophobic or hydrophilic, can be known from the contact angle between the water droplet and the material surface. An example of contact angle being formed by a water droplet and the material surface is shown in Fig. 8.

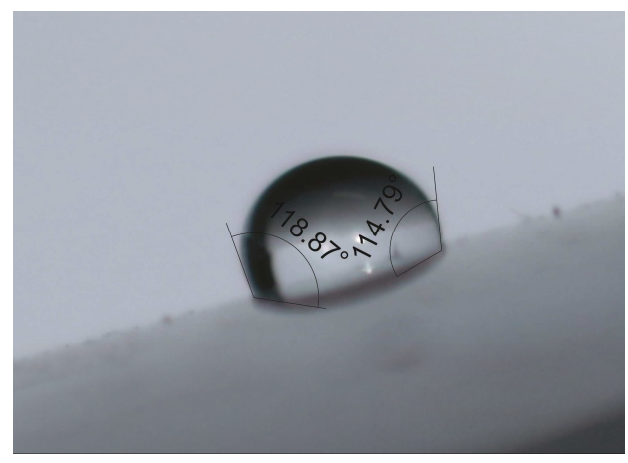

Fig. 8 The contact angle being formed by a water droplet on the surface of a silicone-rubber post-insulator 
Fig. 8 indicates that the average contact angle can be calculated from the left-part angle and the right-part angle of the water droplet on the surface of a silicone-rubber postinsulator. By using the indicated values, the left-part angle of $118.87^{\circ}$ and the right-part angle $114.79^{\circ}$, the average contact angle can be known to be $116.83^{\circ}$ (Eq. 4). As it is larger than $90^{\circ}$, the silicone-rubber being used as the post-insulator material is classified into the group of hydrophobic material. The hydrophobic property of the silicone rubber makes the contact angle between the water and the insulator surface become smaller so that the resulted leakage current will be smaller than that on an insulator made of hydrophilic material.

Due to its contact angle which is larger than $90^{\circ}$, an insulator made of silicone-rubber provides a good option to be considered for high-voltage applications. Another advantage offered by this type of insulator is an environmentally friendly fabrication process, because unlike the ceramic insulator it does not need high temperature process. The weight of a silicone-rubber insulator is also less than that of ceramic or glass insulator.

\section{CONCLUSIONS}

Based on the calculation and analysis of the experiment results, some conclusions can be obtained.

The average contact angle of the silicone-rubber postinsulator of being $116.83^{\circ}$ indicates that the type of insulator falls into the hydrophobic category, since the contact angle is greater than $90^{\circ}$

In dry conditions, the increase in voltage value will be followed by the rise of the leakage current value proportionally, whereas in the wet conditions the higher the wetting rate, the leakage current increase will become more and more nonlinear with the increase of voltage value.

In dry conditions with a voltage increase of $5 \mathrm{kV}$ in the range of $10-30 \mathrm{kV}$, the resulting leakage currents were 9.27 , $14.27,19.20,24.27$ and $29.37 \mu \mathrm{A}$ subsequently, whereas under wet conditions with the highest wetting of 2.512 $\mathrm{mm} / \mathrm{min}$, the leakage current values were $18.5,27.93,45.57$, 71.33 and $118.23 \mu \mathrm{A}$ consecutively.

The application of silicone-rubber insulator in a $20-\mathrm{kV}$ system offers a good performance (up to the highest wetting intensity of $2.512 \mathrm{~mm} /$ minute during the experiment) because the resulted energy losses were relatively small and the resulted leakage current level was below the maximum tolerable standard.

\section{ACKNOWLEDGMENT}

The authors would like to express their gratitude to the Task Force of the World Class University Program and the International Scientific Publication Office of Brawijaya
University for enabling the dissemination of this research paper.

\section{REFERENCES}

[1] N. Nasrul and F. Firmansyah,"Harmonics Impact a Rising Due to Loading and Solution ETAP using the Distribution Substation Transformer $160 \mathrm{kVA}$ at Education and Training Unit in PT PLN," International Journal on Advanced Science, Engineering and Information Technology (IJASEIT), vol. 5, no. 6, pp. 469-474, 2015. [Online]. Available: http://dx.doi.org/10.18517/ijaseit.5.6.603.

[2] M.K.M. Zamani, I. Musirin, S.I. Suliman, M.M. Othman, and M.F.M. Kamal,"Multi-Area Economic Dispatch Performance Using Swarm Intelligence Technique Considering Voltage Stability," International Journal on Advanced Science, Engineering and Information Technology (IJASEIT), vol. 7, no. 1, pp. 1-7, 2017. [Online]. Available: http://dx.doi.org/10.18517/ijaseit.7.1.966.

[3] T.A. Short, Electric Power Distribution Equipment and Systems. Boca Raton, FL: CRC press, 2006.

[4] A.J. Pansini, Guide to Electrical Power Distribution Systems. Boca Raton, FL: CRC press, 2005.

[5] T. Gonen, Electric Power Distribution System Engineering. New York: McGraw Hill, Inc., 1986.

[6] R. Hackam,"Outdoor HV composite polymeric insulators," IEEE Transactions on Dielectrics and Electrical Insulation, vol. 6, no. 5, pp. $557-585,1999$.

[7] PFISTERER SEFAG AG, TECHNICAL FACTS - SILCOSILC SILICONE INSULATORS - Leading Innovations in Silicone Rubber Technology. Switzerland: PFISTERER's Centre of Competence for Overhead Lines, 2015.

[8] R. Chakraborty and S. Reddy, "Performance of silicone rubber insulators under thermal and electrical stress," IEEE Transactions on Industry Applications, vol. PP (99), pp. 1 - 1, 2017.

[9] L. Cheng, L. Wang, Z. Guan, and F. Zhang, "Aging characterization and lifespan prediction of silicone rubber material utilized for composite insulators in areas of atypical warmth and humidity," IEEE Transactions on Dielectrics and Electrical Insulation, vol. 23, no. 6, pp. 3547 - 3555, 2016.

[10] M. Albano, R. T. Waters, and A. Haddad, "Control of leakagecurrent and power dissipation by surface texturing of silicone rubber insulators," in Proceedings of 2016 IEEE Conference on Electrical Insulation and Dielectric Phenomena (CEIDP), Toronto, Canada, 17 - 20 Oct 2016, pp. $841-844$.

[11] K. Zhou, T. Li, Z. Chen, D. Yang, and W. Tao, "The relationship between microstructure and hydrophobicity of service-aged silicone rubber insulators," in Proceedings of 2016 International Conference on Condition Monitoring and Diagnosis (CMD), Xi'an, 25-28 September 2016, pp. 952 - 955.

[12] Arshad, A. Nekahi, S.G. McMeekin, and M. Farzaneh, "Performance comparison of silicone rubber and EPDM insulators in humid and contaminated environments," in Proceedings of 2016 IEEE International Conference on Dielectrics (ICD), Montpellier, France, 3-7 July 2016, 2, pp. $712-715$.

[13] L. Xidong, W. Chao, Y. Yiming, L. Yingyan, G. Yanfeng, and W. Jiafu, "Effective equivalent salt deposit density of polluted silicone rubber insulators in wetting process," in Proceedings of 2014 IEEE Conference on Electrical Insulation and Dielectric Phenomena (CEIDP), Des Moines, USA, 19 Oct - 22 Oct 2014, pp. $271-274$.

[14] J.E. Hobbs, Applied Climatology. Butterworths, London: Wm Dawson \& Sons, 1980.

[15] S.Y. Wang and R.R. Gillies, Modern Climatology. Croatia: InTech, 2012.

[16] BMKG, Condition of Extreme Weather and Climate 2010-2011 (in Indonesian). Jakarta, BMKG Press,

[17] http://data.bmkg.go.id/share/Dokumen/, being accessed on 7 November 2016). 